\title{
Impact of Celebrity Endorsement on Consumer Buying Behaviour in Beauty Soap Industry (With Special Reference to the Consumers in North Central Province in Sri Lanka)
}

\author{
Madhusanka J.D.T. ${ }^{1}$ \\ Department of Business Management, Faculty of Management Studies, \\ Rajarata University of Sri Lanka, Mihintale, Sri Lanka \\ jdtmadhusanka@gmail.com.
}

\begin{abstract}
All of us are consumers. We consume various product and services to fulfil our daily requirements and every time we have to decide what we buy, how we buy, where and when we buy. There are a large number of factors, which influence consumer buying behaviour. But today the firms and marketers are using celebrity endorsement as a major marketing strategy to affect the consumer buying behaviour. Researcher has been taken celebrity endorsement, attractiveness, expertise and the trust worth to measure whether those factors affect for the consumer buying behaviour or not. Hence the purpose of this research is to study the impact of celebrity endorsement on consumers buying behaviour. Furthermore, this study focuses on examining the perception of consumers about celebrity endorsements, examining the celebrity attributes likely to influence consumer purchase intentions and finally the impact of celebrity endorsements on their Consumer Buying Behaviour. The researcher has identified that there is a huge effect on celebrity endorsement towards the consumer buying behaviour while celebrity trustworthiness, expertise and attractiveness has a positive impact on consumer buying behaviour. Today most of the marketers use celebrity endorsement as a strategy to promote their bands therefore, through this research the researcher's scope is to understand the consumers mind set towards the FMCG sector due to celebrity endorsement.
\end{abstract}

Keywords: Celebrity, Buying Behaviour, Endorsement 


\section{Introduction}

The modern day market place is very attractive in terms of purchasing power but equally competitive. Therefore, in order to survive marketers have to develop more innovative ideas which can impact on the consumers. Grabbing attention, informing people and making a specific place in the mind of consumer is the actual challenge for the marketers. Hence today, the modern marketing strategy of most business firms relies heavily on advertising to promote their products to their target markets.

Advertising can be traced back to the very beginning of recorded history. Archaeologists working in the countries around the Mediterranean Sea have dug up signs announcing various events and offers. The Romans painted walls to announce gladiator fights, and the Phoenicians painted pictures promoting their wares on large rocks along parade routes. Modern advertising, however, is a far cry from these early efforts (Kotler \& Armstrong, 2005, p. 455). Today advertisement has become a dominant and leading weapon in all marketing tools due to its positive impact on consumer buying behaviour (Malik, et al. 2013, p. 117). Every advertisement aims to create awareness and stimulate the interest in the minds of customers. So that advertisers employ several marketing techniques to accomplish that target. Celebrity Endorsement is one of these power tool by which advertisers try to leverage the image and identification of the celebrity to promote a product or a company (Atkin \& Block, 1983, as cited in Ahmed, Mir, \& Farooq, 2012, p. 584).

According to Silvera \& Austad (2004) celebrities are people who enjoy the public recognition among a large group of people and possess distinctive qualities like attractiveness and trustworthiness. And celebrity endorsement occur when an individual who enjoys public recognition and who uses this recognition on behalf of a consumer good by appearing with it in an advertisement (McCracken, 1989, p. 310). The use of celebrity is one of the most successful way of gaining consumer attention towards the endorsed products and services. For the last 20 years, trend of using a celebrity to endorse a brand has become very popular. The power of endorsement of celebrities is accepted by everyone and most of the marketing people say that these celebrities have a great impact on altering the buying behaviour of the consumers. It helps to create an impact on consumer minds; attitudes and aid in recall them and finally enhanced sales of their respective products and services. 
There are lots of factors which influence consumer buying behaviour. Therefore, understanding different behaviour of consumers is one of the toughest and challenging task faced by the marketers. Strong positive impact of celebrities in influencing buying behaviour has been widely accepted by marketing gurus across the world. With the help of celebrities consumer attitude can be changed, purchasing intentions can be enlarged and profit can be extended. But the right celebrity has to be picked for the right company. So it is very important to grab consumers' attention and interest among those similar advertisements by using a celebrity who has unique characteristics that can truly effect on consumers' buying behaviour.

Due to the globalization, Sri Lanka attracts many overseas and international companies to enter into its market. In Sri Lanka, most of the consumer goods are endorsed by artists, Film stars, singers, cricketers or athletes. Companies, civil society organizations and government agencies spend billions of money annually placing one form of advertisement using celebrities in the media more specifically through the television advertisements in Sri Lanka. Celebrity endorsements can trigger the purchase of beauty soap products rather than other Fast Moving Consumer Goods (FMCG). In the beauty soap industry of Sri Lanka, Lux has achieved the number one position among the beauty soaps with more than $85 \%$ of households purchasing "Lux" (www.unilever.com.lk). From its inception in Sri Lanka Lux has been using world's leading celebrities as well as Sri Lankan celebrities.

Also in Sri Lankan context this situation can be clearly identified. Celebrity endorsements are also become commonly used strategies by Sri Lankan companies for promoting various types of products, services or brands, especially in soap industry. In Sri Lanka, most of the product brands are endorsed by artists, singers, and young models and sports icons especially by famous cricketers. It is because celebrity endorsement can arouse public awareness and peoples' interest effectively and efficiently. Hence, nowadays, marketers spend huge amount of money on endorsing celebrities like Kumar Sangakkara, Mahela Jayawardene, Lasith Malinga, Chaturika Peries, Bathiya \& Santhush, since they are guaranteed to make a product favourable in eyes of customers. By making a celebrity endorser for a company, they handover a significant part of the company image in the hands of a celebrity. When the celebrity subsequently creates a negative image for him or herself, it will affect to the image of the company. Therefore, it is crucial to select the most suitable celebrity as the endorser for a product of a company. At this point, the effectiveness of the endorsement becomes a muchdebated issue. While there are different models in the literature developed to assess the effectiveness, one of the mostly used one is Ohanian's (1990) Credibility Model. According to 
this model, perceived attractiveness, trustworthiness and level of expertise affect the credibility of the endorser. Source credibility, in turn can affect the buying behaviour regarding a given product or brand. Thus, based on this model the purpose of this study is to test whether the celebrity endorsement can affects buying behaviour of consumer.

\section{Statement of Problem}

Celebrity endorsement is one of the most popular advertising techniques which companies use to create awareness, aid in recall and gain favourable responses about their products and services. To make the advertisement more attractive and effective, advertising agencies and companies are using celebrities. Today, many companies spend millions of rupees each year for endorsing their product by famous celebrities. While celebrity endorsement is good, it can have a negative impact on a product or service because of mismatch between endorser and product. Moreover negative impression about celebrity can be affected or transferred to the product or service they endorsed. And sometimes the product is forgotten and too much focus is on the celebrity, while the focus should be on the product.

Therefore, before choosing a celebrity to endorse a product, marketers must make sure to have a "fit" between the celebrity's image and the product. In fact, it is a difficult task for advertisers to search for celebrities who have an idealistic image in the minds of the consumer and are also an "ideal fit" for their products. Based upon many factors and largely on the type of product to be endorsed, advertisers may choose the celebrities. But it is always a greater challenge for marketers to determine the consumer interest associated with the brand in order to select the right celebrity and to build right brand for celebrity endorsement concept.

A different approach was taken by Zwilling and Fruchter (Zwilling, Moti, and Gila E. Fruchter. 2013). Matching product attributes to celebrities who reinforce the brand: An innovative algorithmic selection model. Journal of Advertising Research 53 (December) who applied a genetic algorithm to an optimal product design model to select the optimal celebrity for a given brand. The model takes into account both product attributes and celebrity traits based on the assumption that consumers construct a brand based on both of these. Based on an empirical test of their model Zwilling and Fruchter (Zwilling, Moti, and Gila E. Fruchter. 2013). Matching product attributes to celebrities who reinforce the brand: An innovative algorithmic selection model. Journal of Advertising Research claims that it outperformed alternative ways of selecting celebrities. However, given the mathematical complexities of their model it seems 
less than likely that it would gain widespread usage among marketing practitioners and academics.

In this way, Communicators are always looking to find out most effective tactics for the brands they represent. Most of the researchers have analysed celebrity's attributes to be a good endorser, but is it enough to build a good strategy?

Though there are extensive researches which show that consumers are generally responsive to celebrity endorsements, it is unclear what impact a celebrity endorsement would have on many specific types of products and celebrity influence on consumer behaviour. Hence, this study attempts to identify the consumer side of celebrity advertisement. An attempt has been made to find out whether the celebrities create the awareness, recall of the brands, change the purchasing intention about brands, especially in soap industry, on which category of product will be bought through the influence from them and which section or segment could be influenced by the celebrities on consumer buying behaviour or can change the consumer attitude towards the product.

Although there is a direct connection in celebrity endorsement with the beauty soap industry, there is lack of researchers conducted to measure the responsiveness regarding the consumer behaviour towards the beauty soap industry with respect to celebrity endorsement strategies.

To prevent the issue of theoretical and empirical gap in an effective and efficiency way the research suggest conducting this research.

\section{Objective/s of the Study}

1. To identify the relationship between trustworthiness of celebrity and consumer buying behaviour

2. To identify the relationship between expertise of celebrity and consumer buying behaviour

3. To identify the relationship between attractiveness of celebrity and consumer buying behaviour

4. To identify the relationship between celebrity endorsement and consumer buying behaviour 


\section{Review of Literature}

Study of consumer behaviour is very important, because intentionally or unintentionally we all are consumers in the market. Nowadays, the philosophy of marketing production has been tending to the important marketing trend of consumer behaviour. In the marketing field some questions have created people as a marketer; hence, we must pay attention to them and provide reasonable answers to them. Considering the fact that, a marketer is seeking to identify the needs and demands of our customers and does the appropriate actions to meet those needs and desires, as well as they should understand the consumer behaviour.

\section{Consumer Buying Behaviour}

The topic of consumer behaviour is one of the massively studied topics by the researchers and marketers in the past and still being studied. One of the common views is that understanding consumer behaviour has become a factor which has a direct impact on the overall performance of the businesses (Kotler \& Keller, 2012). The Table 1 presented the definitions of some authors and findings of them below.

\section{Table 1: Definition of Consumer Behaviour}

\begin{tabular}{|c|c|c|}
\hline Authors & How to define consumer behaviour & Findings \\
\hline $\begin{array}{l}\text { Faison and } \\
\text { Edmund (1977) }\end{array}$ & $\begin{array}{l}\text { "The assumption that people have series of needs } \\
\text { which lead to drive state." }\end{array}$ & Needs \\
\hline Engel, et al. (1986) & $\begin{array}{l}\text { "Those acts of individuals directly involved in } \\
\text { obtaining, using, and disposing of economic } \\
\text { goods and services, including the decision } \\
\text { processes that precede and determine these acts" }\end{array}$ & $\begin{array}{l}\text { Acts, } \\
\text { individuals }\end{array}$ \\
\hline Kotler (1994) & $\begin{array}{l}\text { Consumer behaviour is the study of how } \\
\text { people buy, what they buy, when they buy and } \\
\text { why they buy. }\end{array}$ & \\
\hline $\begin{array}{l}\text { Solomon et al. } \\
\text { (1995) }\end{array}$ & $\begin{array}{l}\text { Consumer is the study "of the processes involved } \\
\text { when individuals or groups select, purchase, use, }\end{array}$ & $\begin{array}{l}\text { Process, } \\
\text { needs, }\end{array}$ \\
\hline
\end{tabular}




\begin{tabular}{|l|l|l|}
\hline & $\begin{array}{l}\text { or dispose of products, services, ideas, or } \\
\text { experiences to satisfy needs and desires" }\end{array}$ & $\begin{array}{l}\text { individuals, } \\
\text { group }\end{array}$ \\
\hline Schiffman (2007) & $\begin{array}{l}\text { "the behaviour that consumers display in } \\
\text { searching for, purchasing, using, evaluating, and } \\
\text { disposing of products and services that they } \\
\text { expect will satisfy their needs" }\end{array}$ & Acts, \\
\hline
\end{tabular}

\section{Key Concepts of Consumer Behaviour}

Consumer behaviour is motivational: The main question that arises in this context is that "why consumer behaviour occurs?". Answer to this question is included in the definition of consumer behaviour. Consumer behaviour is met the needs and demands of him. Behaviour is a tool to achieve objectives and targets of consumers which derives from their needs and desires (Wilke, 2000).

Consumer behavior includes many activities: All consumers have differences in terms of thoughts, feelings, and decisions and ... with each other. Marketers must pay attention to the activities of consumers, some consumers activities are: See the advertisement, purchase decision, the decision about how to pay (cash, credit) and, Consumer behavior is a process: Consumer behavior including the selection, purchasing and consumption of goods and services (Rostami, 2001).

Consumer behavior at different times has different complexity. Consumers purchase different product and services from different sellers after analyzing there marketing strategies. To purchase some goods they are consider three - process steps of consumer behavior. While buying some goods (goods that are consumed regularly) is very simple and does not require multiple steps. Customers try to make the buying process simple through trusting others, loyalty to the brand and; Consumer behavior includes different roles: Consumers in different time can play each of the three roles those are information searching, evaluation and purchase decision. When we buy something for our self we can play those 3 roles (Golchinfar, 2006). Some times by using others' opinion in the case of buy something for someone, we can play an individual role. 
Consumer behavior is influenced by external factors such as culture, subculture, social classes, location and etc. These can be effects in short, medium or long term.

Consumer behaviour is different for different people: Because people have different desires and needs, so their behaviour is different. And different consumer behaviours make the consumer behaviour more difficult. To solve this problem categorization of the market is possible (Abbasi \& Torkamani, 2010).

\section{Consumer Perception Factors}

Perception is a mental process, whereby an individual selects data or information from the environment, organizes it and then draws significance or meaning from it (Perceived fit, Quality, Packaging, and Familiarity with a channel, Brand awareness, and Family influence).

\section{Factors Influencing Consumer Behaviour}

Purchase decision is result of each and every one of these factors. An individual and a consumer is led by his culture, subculture, social class, membership groups, family, personality, psychological factors, and is influenced by cultural trends as well as from his social and societal environment. Consumers' buyer behaviour is influenced by four major factors; 1) Cultural, 2) Social, 3) Personal, 4) Psychological. However to find the relationship the following hypothesis is generated:

H1: There is a positive relationship between Trustworthiness of the celebrity and buying behaviour of the consumer

H2: There is a positive relationship between Expertise of the celebrity and buying behaviour of the consumer

H3: There is a positive relationship between Attractiveness of the celebrity and buying behaviour of the consumer

H4: There is a positive relationship between celebrity endorsement and consumer buying behaviour

\section{Methodology}

A conceptual framework is a conceptual model of how one theorizes or makes logical sense of the relationships among the several factors that have been identified as important to the research problem (Sekaran, 2003, p.87). The theoretical framework discusses the 
interrelationships among variables. It helps to generate hypotheses and to understand the dynamics of the situation.

In this study, the researcher tries to emphasize whether there is an impact of celebrity endorsement on consumer buying behaviour in North Central Province in Sri Lanka. For this purpose the researcher has developed the conceptual framework based on the source credibility model developed by Ohanian at 1990.

Credibility is seen as a multidimensional concept that is related to various communication sources. With regard to the problems of previous factor model studies of source credibility, an approach towards generalization based on several measurements of previous studies is chosen in order to explore and to analyze the multidimensional structure of source credibility in marketing communication. The identified dimensions of credibility can also function as clues for the enhancement of a source's credibility. This is of particular interest to marketers since source credibility has an impact on message receivers' attitudes, intentions, and behaviours. In a meta analytic study, Wilson and Sherrell (1993) showed that source credibility has a positive persuasive impact: on average 7.4 percent of the explained variance of the dependent variables were due to a low- vs. high source credibility manipulation. Given our knowledge of a strong relationship between attitudes and subsequent behaviour (Fazio 1990), the importance of the persuasive impact of source credibility in marketing communication is obvious. Conceptual framework is presented in figure 1 below.

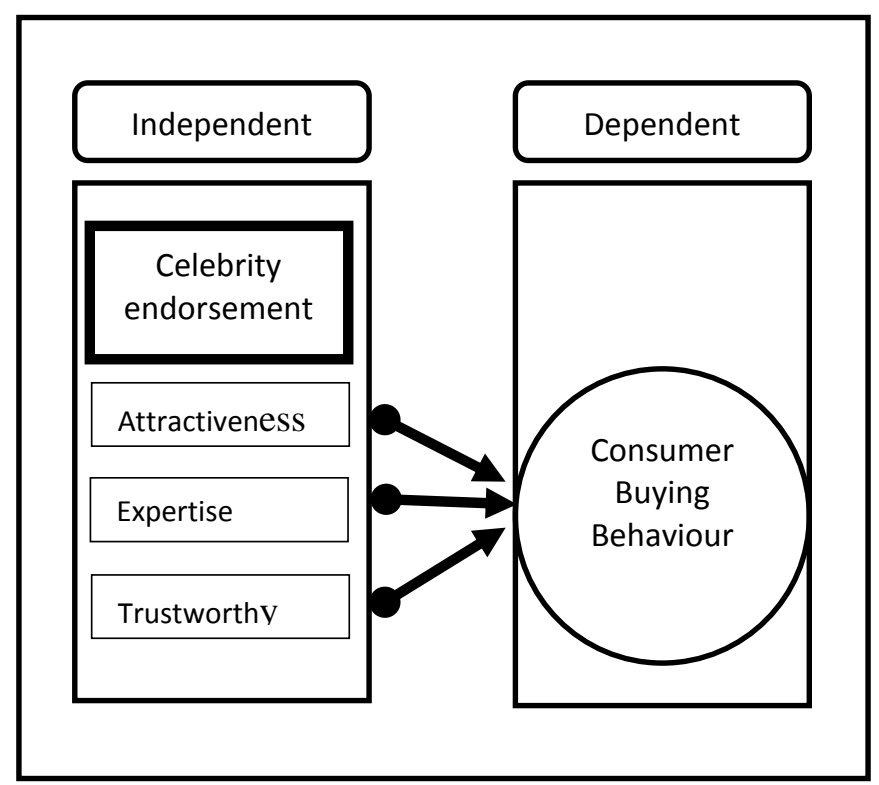

Fig. 01: Conceptual Framework of the Study

Source: Adopted from Ohanian 1990. 


\section{Sample Frame}

The sampling frame describes the list of elements from which the sample is actually drawn. Ideally, it is a complete and correct list of population members only (Cooper \& Schindler, 2006, p. 453). In this research study, the limitation of respondents are aged between 17 and 45 who are living in the North Central Province and who can read and understand scale wordings, regardless of gender and other demographic differences can be identified.

\section{Data Analysis Techniques}

The data analysis techniques have been used based on the previous studies. The regression analysis has been used to predict the value of the dependent variable based on the value of the independent variable. So to measure the celebrity and consumer attitude measures of dispersion have been used.

In order to achieve the purpose of the study and to satisfy the objectives of the study in a measurable way (Statistically), the following statistical techniques were employed to analyze the survey data of the sample. All the data analysis procedures were accomplished with the assistance of SPSS software.

\section{Testing of Hypothesis}

Analysis regarding Dependent and independent variable

\section{Descriptive Statistics}

\begin{tabular}{|l|r|r|}
\hline & Mean & Std. Deviation \\
\hline Consumer Behaviour & 2.9184 & .66933 \\
Celebrity Endorsement & 2.6585 & .58749 \\
\hline
\end{tabular}

\section{Correlations}

\begin{tabular}{|c|c|c|c|}
\hline & & Consumer Behaviour & Celebrity Endorsement \\
\hline \multicolumn{2}{|c|}{ Pearson Correlation Consumer Behaviour } & 1.000 & \\
\hline & Celebrity Endorsement & .656 & 1.000 \\
\hline \multirow[t]{2}{*}{ Sig. (1-tailed) } & Consumer Behaviour & & \\
\hline & Celebrity Endorsement & .000 & \\
\hline
\end{tabular}




\section{Regression analysis - Dependent and Independent variables}

\begin{tabular}{|l|c|r|r|r|}
\hline & & & & \\
Model & $\mathrm{R}$ & R Square & Adjusted R Square & Std. Error of the Estimate \\
\hline 1 & $.656^{\mathrm{a}}$ & .430 & .428 & .50624 \\
\hline
\end{tabular}

a. Predictors: (Constant), Celebrity Endorsement

Relationship between variables $(\mathrm{R})=0.656$

Explanatory power $(\mathrm{R}$ Square $)=0.430$

The Multiple $\mathrm{R}$ for the relationship between the set of independent variables and the dependent variable is 0.656 , which would be characterized as strong using the rule of thumb than a correlation less than or equal to 0.20 .

$43.0 \%$ of total variation is explained by the model (correlation is 0.65 ). This means that $43.0 \%$ of the variation in Consumer Buying Behaviour can be explained by the variability in the Celebrity Endorsement.

\begin{tabular}{|ll|r|r|r|r|r|}
\hline \multicolumn{1}{|c|}{ ANOVA $^{\mathbf{b}}$} \\
\hline 1 & $\begin{array}{c}\text { Sum of } \\
\text { Model }\end{array}$ & Rquares & \multicolumn{1}{c|}{ df } & Mean Square & \multicolumn{1}{c|}{ F } & Sig. \\
\hline & Regression & 56.432 & 1 & 56.432 & 220.198 & $.000^{\mathrm{a}}$ \\
& Residual & 74.833 & 292 & & & \\
& Total & 131.265 & 293 & & & \\
\hline
\end{tabular}

a. Predictors: (Constant), Celebrity Endorsement

b. Dependent Variable: Consumer Behaviour

\section{Coefficients $^{\mathrm{a}}$}

\begin{tabular}{|c|c|c|c|c|c|}
\hline \multirow[b]{2}{*}{ Model } & \multicolumn{2}{|c|}{$\begin{array}{c}\text { Unstandardized } \\
\text { Coefficients }\end{array}$} & \multirow{2}{*}{$\begin{array}{c}\begin{array}{c}\text { Standardized } \\
\text { Coefficients }\end{array} \\
\text { Beta }\end{array}$} & \multirow[b]{2}{*}{$\mathrm{t}$} & \multirow[b]{2}{*}{ Sig. } \\
\hline & B & Std. Error & & & \\
\hline (Constant) & .932 & .137 & & 6.804 & .000 \\
\hline $\begin{array}{l}\text { Celebrity } \\
\text { Endorsement }\end{array}$ & .747 & .050 & .656 & 14.839 & .000 \\
\hline
\end{tabular}

a. Dependent Variable: Consumer Behaviour 
The $b$ coefficient associated with strength of affiliation (0.747) is positive, indicating a positive relationship between Celebrity Endorsement and Consumer Buying Behaviour.

\section{Conclusion and Recommendations}

The statistical results indicated that there was a positive impact of celebrity trustworthiness, expertise and attractiveness on consumer buying behaviour. Moreover, results showed that a majority of the consumers agreed that celebrity endorsers enhanced brand awareness. The consumers agreed that the celebrity endorser would be able to capture their attention towards the brand whenever they saw the advertisement featuring the celebrity. The respondents concurred that the celebrity endorser helped them to easily identify product because of the presence of these celebrities that the product is noticed and remembered by the consumers and differentiate the various product brands in the market which led to better product knowledge hence being more confident in their purchase decisions. It is evident from the study that celebrity endorsement enhances product information and creates awareness among consumers. It helps them to recall the brands of the Soap Industry at the time of purchase and the purchase attitude change of consumers is influenced by the celebrity endorsement factors.

Furthermore, it was proved through the analysis that credibility of the celebrity has maximum effect on consumer behaviour. Hence, marketing firms must preferably select those celebrities who command a high credibility in the minds of consumers. These outcomes clearly show that various dimensions engaged in celebrity studies have positive on buying behaviour of consumers. The results reinforce the view of advertisers that celebrities do influence consumer behaviour in some way or the other.

\section{Recommendation}

The research outcomes bring practically important results for marketers to consider while choosing a celebrity for an advertisement. Different consumers will have different preference on the celebrity endorsers and their buying behaviour can only be triggered by a particular kind of celebrity endorsers. In order to make the effect a significant one, there are some suggestions to marketers.

First, the selection of celebrity endorsers with the right attributes is very important to the success of celebrity endorsement. It is because celebrity endorsements can help to create and reinforce the value and image of the product and brand. Thus the markets must carefully 
evaluate the celebrities and make sure the image which perceived by the target customers are positive. Therefore marketers can choose celebrities according to the important attributes required to influence a set of population. For instance males and females think that trustworthiness is the most important dimension that the celebrity endorsers must possess, so the prerequisite of the companies is to select the celebrity endorsers who are highly trustworthy. Corporations which want to promote their products through celebrity endorsement should make sure that the endorser well aware and aligns with the core values of the company and understands the objectives of the advertising objectives. Additionally, marketers should bound celebrities to use the products endorsed by them since majority of people believe that celebrities don't use the products they endorse. This will caused increase the credibility of celebrities as well as the product among the consumers.

Moreover, the markets must understand the relationships between trustworthiness, attractiveness and expertise. Attractiveness can give a positive impression of trustworthiness and expertise to the celebrities and the products. The company must have thorough consideration and sufficient research before the endorsement takes place. They must understand the preference and purchase behaviour of their target customers. So that the marketers can react to customer and market changes rapidly.

Negative information about the celebrities should also be an area of consideration by the marketers, because People who are affected by such negative information may completely grasp a false impression about the advertisement which in turn might prove harmful to the product or brand. Therefore managers should be careful in handling such situations as failure and downfall of reputation might result in serious risks and loss to the firm.

In summary, celebrity endorsement is an effective promotion tool. The companies must select the right celebrity endorsers in order to grab the attentions and arouse the interest of the target customers.

\section{Suggestions for future study}

This study has focused only consumers within the age bracket 17-45 years; future research can be undertaken targeting different age groups especially senior citizens in Sri Lanka which would probably bring to light different perceptions regarding the topic in hand. And also this research study is limited to only Products of Fast Moving Consumer Goods industry, therefore

future studies should attempt to examine broader area across different categories of products 
as well as in the service industry. And this research area is only conducted in North Central Province and future studies can expand beyond North Central Province to rural area as well as to other provinces. This in essence will create opportunity for generalization and comparisons across different areas of countries and across different product and service industries.

This research was conducted based on the source credibility model which was found by Ohanian at 1990. There is an urgent need for the development of a comprehensive model that will explain all those factors that predict success or failure of a celebrity in product endorsement. Therefore, another models like the "Meaning Transfer Model" by McCracken (1989) needs to be looked into with greater depth and examination. Study on how the meaning is essentially transferred from the celebrity to the product and how the advertisements accomplish in this area calls for attention. Reasons on how the media selects such celebrities and how the consumers are attracted towards their attributes which in turn leads to buying behaviour can also be investigated.

Another important aspect to be explored can be how negative publicity can affect the purchase intention of consumer with reference to low and high involvement product and services. Negative publicity of the celebrity associated with the product can destroy the brand and it may take lot of time to recover the same image. Moreover, how easily people can accept a celebrity with a negative publicity to be a brand endorser is also of special interest.

Another major area to explore is demographical area. Attitudes and perceptions of people differ on various different basis for instance age, gender, country, income level etc. From the marketer point of view it is important to understand that consumers are governed by their culture and values. Moreover, the limitations highlighted in the earlier sections provide a broad platform for future research.

\section{References}

Dzisah, W. E., \& Ocloo, C. E. ( 2013). Celebrity Endorsement and Consumer Buying Behaviour;Enhancing the Promotion Function of Marketing in the Central Business Area of Accra, Ghana. European Journal of Business and Management, Vol.5, 197-209.

Erdogan, B. Z. (1999). Celebrity Endorsement: A Literature Review. joumal of Marketing Management, 15, 291-314. 
Faghani, E., \& Miremadi, A. ( 2012 ). An Empirical Study of Consumer Buying Behavior and Its Influence on. International Business and Management, Vol. 5, 146-152.

Fouladivanda, F., Pashandi, M. A., Hooman, A., \& Khanmohammadi, Z. (2013, January). The effect of Brand Equity on Consumer Buying Behavior in term of FMCG in Iran. Interdisciplinary Journal Of Contemporary Research In Business, Vol 4, 945-957.

Kotler, P. (2000). Marketing Management: Millenium Edition (10th ed.). New Jersy: PrenticeHall.

Kotler, P., \& Armstrong, G. (2005). Principles of Marketing (11th ed.). New Delhi: Prentice Hall of India.

LING, A. P. (2007). The Impact of Marketing Mix on Customer Satisfaction: A Case Study Deriving Consensus Rankings. 1-138.

Malhotra, N. K. (2007). Marketing Research: An Applied Orientation (5th ed.). New Delhi: Pearson Education,Inc.

Malik, M. E., Ghafoor, M. M., Iqbal, H. K., Ali, Q., Hunbal, H., Noman , M., et al. (2013). Impact of Brand Image and Advertisement on Consumer Buying Behavior. World Applied Sciences Journal, 23(1), 117-122.

McCracken, G. (1989). Who is the celebrity Endorser? Cultural Foundations of the Endorsement Process. Journal of Consumer Research, 16, 310-321.

Modi, S. (2007). Impact of Celebrity Endorsements on Consumers' Purchase Intentions and Overall Brand. 10-37.

Ohanian, R. (1990). Construction and Validation of a Scale to Measure Celebrity Endorsers' Perceived Expertise,Trustworthiness, and Attractiveness. Journal of Advertising, Vol. 19, No. 3, pp. 39-52.

Ola, O. s., Owomoyela , S. k., \& Oyeniyi , k. o. (2013, March). Investigating The Impact Of Marketing Mix Elements On Consumer Loyalty: An Emprical Study On Nigerian Breweries Plc. Interdisciplinary Journal Of Contemporary Research In Business, Vol 4, 485-496.

Saunders, M., Lewis, P., \& Thornhill, A. (2009). Research methods for Business Students (Fifth ed.). Rotolito Lombarda, Italy: Pearson Education. 
Schiffman, L. G., \& Kanuk, L. L. (2000). Consumer Behaviour (Sixth ed.). New York, U.S.A: Prentice Hall of India Private Limited.

Sekaran, U. (2000). Research Methods For Business:A Skill-Building Approach For management (4th ed.). New York, U.S.A: John Wiley \& Sons, Inc.

Solomon, M., Bamossy, G., Askegaard, S., \& Hogg, M. K. (2006). Consumer Behaviour:A European Perspective (Third ed.). new jursey, U.S.A: Prentice Hall Financial times, Europe.

YI, A.-Y. P. (2012). Effects Of Celebrity Endorsement on Consumer Purchasing Intention of Apparel Products. 20-22.

Zafar, Q. U.-A., \& Rafique, M. (n.d.). Impact of Celebrity Advertisement on Customers' Brand Perception and Purchase Intention. Asian Journal of Business and Management Sciences, 5367. 